\title{
Douglas Blandy
}

\section{INTRODUCTION}

On January 7, 1982 four persons labeled moderately mentally retarded by the Franklin and Fairfield County, Ohio, Boards of Mental Retardation and Developmental Disabilities began an apprenticeship in the book arts (typesetting, printing, papermaking, binding) at The Logan Elm Press and Paper Mill. This workshop is the arts-of-the book laboratory of The Ohio State University Department of Art Education. At Logan Elm these apprentices work with book artists, designers, graduate/undergraduate students in Art Education and Special Education for the purpose of publishing literature which is accessible to persons who cannot read the alphabet. Two problems in Art Education and Special Education encouraged the participation of this group. These problems will be the subject of this paper.

\section{THE PROBLEMS}

Poet Robert Graves, in his autobiography Goodbye To A11 That, remembers a visit to a twenty thousand volume 1 ibrary in Quar Abbey, England. The librarian asked Mr. Graves if he would like to read history, botany or engineering. Mr. Graves asked for poetry. This 1 ibrarian replied that poetry was not a part of his library for it cannot be regarded as "improving". This response indicates that this librarian's stacks were lined with books meant for the practical improvement of the individual rather than for enlightenment. The liberal arts were not to be found on this library's shelves.

The content of the education often designed for the so-called mentally retarded person is similar to the book collection of the Quar Abbey Library because it also tends only to be practical and useful. Definitions of mental retardation, like the American Association of Mental Deficiency definition, which stress a lack of intelligence and deficits in adaptive behavior have contributed to this narrowly practical emphasis in the curriculum. For example, the National Committee, Arts for the Handicapped's Arts for Learning Curriculum promotes not art education, but social ski17s development, conceptual skills development, perceptual motor integration, sensory motor integration, gross motor development and language development. Art activities are prescribed to reinforce development in these learning areas. An unsettling analogy can be drawn between the use of the arts in this curriculum and the use of edibles in some behavior management schemes.

Curricula, like this one developed by the National Committee, are inherently flavored for through them teachers attempt to reinforce practical learning without a foundation in liberal arts concepts. At best this is unintentional wrong-headedness and at worst it reflects a 
discriminatory attitude based upon a perception of those persons called mentally retarded as incapable of enjoying or cultivating the liberal arts experience.

A transformation in the basic structure of the current non-liberal arts education of those called mentally retarded is necessary. This is a transformation which will be plagued by problems, one problem being that at present many liberal arts forms are not easily accessible to the mentally retarded person because of handicaps associated with that disability. Poetry and the book arts are two of those forms.

For example:

who are you, 1ittle $i$

(five or six years old)

peering from some high

window; at the gold

of november sunset

(and feeling: that if day

has to become night

this is a beautiful way)

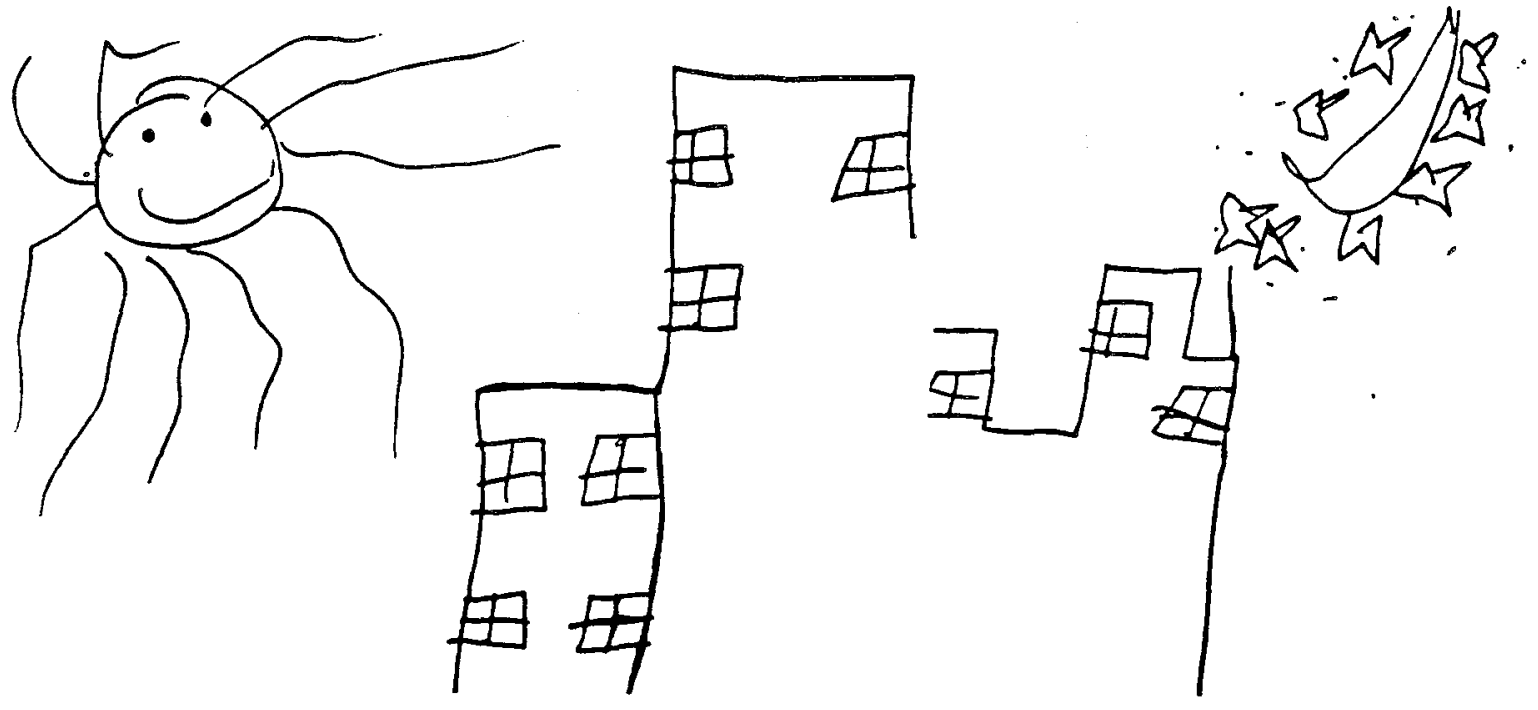

Douglas Blandy 43 
Fanny Norris drew this picture following the recitation of "52" to her by Lisa Russell an OSU Art Education Department student. Norris' picture translation of the poem demonstrates her understanding of it. The drawing is consistent with the poem's reference to a location in a "high window" and the feeling of "day" becoming "night." Norris represents the beauty of this transition by rendering the sun radiant, smiling to a crescent moon surrounded by stars which twinkle. This drawing does not indicate Norris' understanding of each and every word or phrase of the poem. It represents a general comprehension.

Norris is a student in the Frankl in County, Ohio Board of Mental Retardation and Developmental Disabilities school age program for the moderate, severe and profoundly mentally retarded. She cannot read "52" without great 1 abor and verbal prompts from a friend. Her reading lacks joy; however, Norris' drawing does indicate that the content of this poem can appeal to, and be understood by her, if presented in an accessible format. Norris demonstrates the truth in $A$. E. Housman's belief that "meaning is of the intellect, poetry is not" (1952, p. 86).

Housman, and my own experience tell me that the comprehension of poetry is a matter of being sympathetic or empathetic to the feelings communicated by the poet. The degree to which one is in sympathy or empathy to another may be last of all known to the intellect. Yeats (1952) writes that our thoughts may first ". . . rush out to the edges of our flesh" ( $p .106)$. I have never met anyone who was not in some way capable of being sympathetic or empathetic. For this reason the comprehension and appreciation of poetry is not unique to some and impossible to achieve by others. However, I have met many people who are unable to be sympathetic or empathetic in certain instances because of the use of an inaccessible means of communication.

Problem One

So-called moderately mentally retarded persons can comprehend the concepts of recited poetry; however, they cannot read a poem when printed in a phonetic alphabet. A contradiction exists between the ideas that these persons can grasp and the form in which those ideas are presented.

About the moderately mentally retarded and their reading, Kirk (1973) writes: "In general, trainable children do not learn to read from even first grade books. Their ability is 1 imited to reading and recognizing their names, isolated words and phrases, common words for protection and other signs which they counter in a community." Kirk's observations must, in part, be based upon the effect of his subjects' stage of cognitive development on their capabilities for reading. From a Piagetian point of view the moderately mentally retarded person reaches a stage of cognitive development equal to the child of six or seven years. This is referred to as the stage of preoperations.

Reading requires the derivation of meaning from written signs. To do this an individual must be able to recognize written words as signs which bear no verbal or visual relationship to what they present. This 
usually is not achievable until the stage of concrete operations at about age seven or eight. Because signs are phonetically constructed they require the individual to be adept at classification. For instance, each vowel has a number of different pronunciations which are classifiable as rules or exceptions to the rule. This skill also is not characteristic of children under seven (Wadsworth, 1978).

However, to only experience poetry through an oral or signed performance is not an acceptable situation because not every poem is best encountered through recitation. Cummings' "52" ceases to be a Cummings" poem without the eccentricities and idiosyncracies of its written form. Further, the performed poem provides a very different experience than the poem read. "52" will become as varied as the number of instances of its performed interpretation. The listener is denied the opportunity to consider his own interpretation. The relative neutrality of the printed poem allows for this. The printed poem promotes repeated readings and is a subject for study and contemplation at the reader's convenience. This is without the contamination of a performer's interpretation. Finally, the recitation of poetry is not appropriate for every time and place. Audio and video tapes are not always available. The gleeman does not fit easily into the back pocket.

Despite the oral tradition of poetry there can be no denial of the importance of its written form. An alternative to phonetic reading material must be explored to negate the contradiction that exists between the oral, signed and written presentation of poetry for Ms. Norr is and persons like her. Logographs offer one area of exploration. This exploration in poetry would not be totally unfounded. Ernest Fenollosa (1968), in The Chinese Written Character as a Medium for Poetry, argues for the use of logographs to notate poetry because of their richness as opposed to the "poorness" he saw in the alphabetic system. Charles 01 son uses hieroglyphics and ideograms in his poetry to resist the contamination of meaning in contemporary language (Rothenberg, 1981). Poet/printer Clifford Burke's idiosyncratic poetry is based upon the logographic symbols of ancient native American petroglyphs.

Logographic symbol systems have proven to be accessible to children with reading difficulties (Rozin, Poritsky and Stotsky, 1971). A study by Howse, Hanley and Magid, 1980, indicates that the moderately mentally retarded can learn to read logographs. Blissymbols were one such system mentioned by the researchers as needing further exploration. These standardizes symbols are the focus of international research and resource centers. Blissymbols are currently being used by physically handicapped and mentally retarded individuals who cannot speak or sign.

Problem Two

Many so-called moderately mentally retarded persons, because of their inability to read, are unfamiliar with books (except those easy vocabulary books designed for the pre-school youngster which should hold little or no interest for the youth or adult), the book arts and "fine printing." The 
book arts consist of papermaking, hand typesetting, printing, and binding. "Fine printing" is the successful manipulation of these arts in combination. On "fine printing" poet/printer C1 ifford Burke (1975) writes: "Looking at fine printing involves all of the senses, and we 'see' a well made book as an integrated object bringing together the kinetic sense of weight and of pages turning, the feel of the pages and of binding material, the subtle dent of type impressed into paper and many other sensory discretions..." The book, and the arts it combines, can be viewed as a multi-sensory object providing a multi-sensory/reinforcing aesthetic experience for any person who experiences effectively through a multi-sensory approach. Therefore, the book and the book arts can be a very appropriate source of contemplation and participation.

Fine printing is the work of the non-commerical small press 7 ike The Logan Elm Press. Some of these presses are located in public and private schools, colleges and universities. These small operations are often directed by people with a willingness to print publications for discrete and specialized markets. Published titles tend to be diverse and experimental. Poetry is one staple of the small press; however, American small presses are almost universal in their reliance upon the phonetic alphabet. Only a very limited number of writers are working with logographic systems.

The exploration of an alternative to the phonetic alphabet, for a discrete market of persons, is an expansion a small press could comfortably pursue, one reason being that it would expand its patronage to an untapped population. In addition, it would also bring attention to those others who are experimenting with logographs for an uncertain audience.

The mentally retarded can be involved in this expansion of the small press. The intellectual and motor skills involved in making paper, setting type, printing, binding and other support services are not more difficult than many jobs mastered by the retarded persons in existing vocational and pre-vocational programs. Many industries which employ mentally retarded persons are currently seeking and developing cottage industries to augment inconsistent and vanishing contract work from outside sources. Running a small publishing operation and/or a handmade paper mill is an alternative, to the outside contract, that these industries could consider.

It is conceivable that a small press could include persons called mentally retarded in their operations. If these operations were devoted to printing literature in a form accessible to these persons this would offer a unique opportunity. These individuals would not only be in contact with accessible writings, but also the craft through which that literature is communicated.

CONCLUSION

These problems in Art Education and Special Education demanded that Fanny Norris, and three others called moderately mentally retarded, be apprenticed at Logan E]m. In the context of this Press the labels that they brought to it now mean very little. Ms. Norris currently assists 
student teachers in the Art Education Department Saturday Book Arts Workshop and another apprentice is being considered for admittance into a graphics communication vocational training program. The B1 issymbol books of poetry that they helped produce are being distributed internationally to non-alphabetic readers.

\section{REFERENCES}

Burke, Clifford. Looking at fine printing. San Francisco: Cranium Press, 1973.

Fenollosa, Ernest. The Chinese written character as a medium for poetry. San Francisco: City Lights Books, 7968.

Graves, Robert. Goodbye to al1 that. Doubleday and Co., Inc., 1957.

Houseman, A. E. The name and nature of poetry. The creative process. Ghiselin, Brewster, ed. Mentor Books, 1952.

House, B. S., Hanley, M. S., and Magid, D. G. Logographic reading by TMR adults." American Journal of Mental Deficiency, 1980, 1, 2.

Kirk, S. A. Educating exceptional children. Boston: Houghton Mifflin, 1972.

The National Committee, Arts for the Handicapped. Arts for learning. Washington D.C.: The National Committee, Arts for the Handicapped.

Rothenberg, Jerome. Pre-faces and other writings. New York: New Directions Books, 1981.

Rozin, P. S. Poritsky and Sotsky, R. American children with reading problems can easily learn to read English represented by Chinese characters. Science, 1971.

Wadsworth, Barry J. Piaget for the classroom teacher. Longman, Inc., 1978.

Yeats, William Butler. The thinking of the body. The creative process. Ghiselin, Brewster, ed. Mentor Books, 1952. 